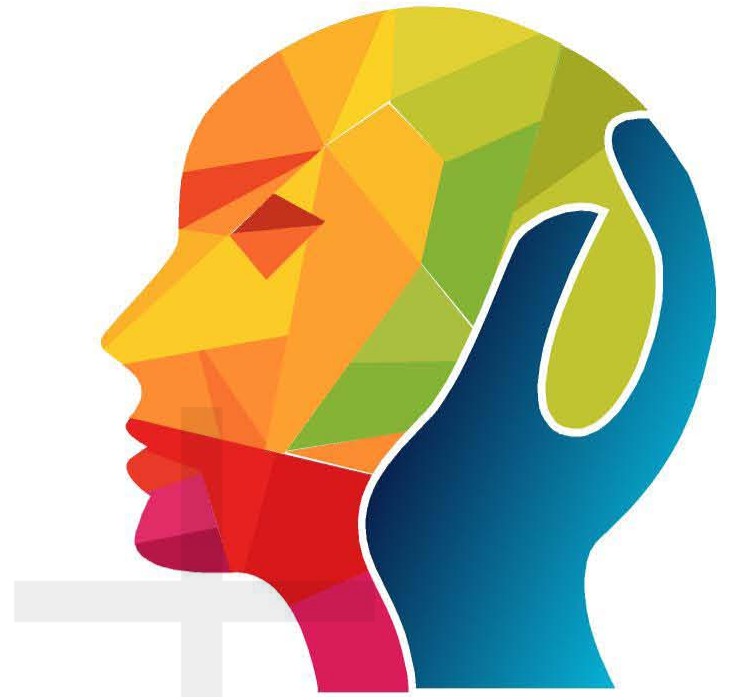

\title{
La publicidad, creadora de mitos modernos
}

Por Mauricio Ramírez

Catedrático de la Universidad

Centroamericana José Simeón Cañas

Máster en Comunicaciones

\section{Introducción}

n el canto XII de la Odisea se relata cómo Ulises advertido, por la diosa y hechicera Circe, del peligro que le acechaba en su regreso a casa, pudo evadir el temible peligro del canto de las Sirenas. Ellas hechizaban a los que por allí pasan, sentadas en un prado y desde donde atraían a los marinos con sus sonoros cantos. La diosa le advirtió que ese canto le podía hacer perder la razón y hacer que sucumbiera ante sus influjos, le dio instrucciones precisas que se atara bien de pies y manos al mástil del navío y que a sus hombres les taponara con cera en los oídos, de tal suerte que jamás pudiesen escuchar el canto emitido por las Sirenas, ya que una vez cualquier mortal escuchaba esos cantos su destrucción estaba asegurada. Así lo hizo Ulises, y ordenó que sus hombres lo ataran firmemente de los pies y las manos al mástil del barco y les instruyó que aunque él les pidiera que lo soltasen no lo hicieran. De esa forma Ulises logró evadir el canto de las Sirenas, que hechizan a todos los hombres.

Este relato es oportuno para introducir un asunto que es muy importante en nuestra sociedad, como es el poderoso canto de la publicidad. Se dice que a través del efecto de la publicidad, como cantos de Sirena, el hombre ve disminuida su capacidad de raciocinio y que, por ese influjo, el hombre pierde parte de su libertad. Para comprender la influencia publicitaria no hay nada más que ver los escaparates de los negocios y entender cómo nos crea sueños aspiracionales para nuestra vida, pero por demás, sueños inveterados. Si hay algo que ha permitido comprender mejor el fetichismo de la producción, es a través de la publicidad. Los productos se nos presentan como algo único, absolutos, separados de su fuente que es quien los produce. Walter Benjamín va un paso delante de esta comprensión del marxismo ortodoxo y llama fantasmagóricos a los productos1. Los productos no solo están fetichizados, pero están presentados como si nadie los hubiese producido, con sus empaques tan especiales que da la sensación que no ha salido de ningún proceso de producción, como si fueran fantasmas que cobran vida por sí mismos y se nos ofrecen como la solución mágica para el logro de nuestra felicidad.

La técnica y ahora la tecnología siempre ha sido imaginada como un aspecto que ayude al hombre en su vida, que le posibilite lograr una mejor calidad de vida para poder disponer de más tiempo para su disfrute y su desarrollo personal. Resulta que esto no ha sucedido y más bien la técnica ha instrumentalizado al hombre y lo ha vuelto parte de todo el proceso productivo, a tal grado que en vez de liberarlo lo ata. Uno podría fácilmente imaginar que con tanta técnica a disposición del hombre, la calidad de vida debiera ser mejor, pero esto es algo muy cuestionable. Ahora ya no nos importa tanto la fábrica, ahora es más importante el lugar donde se consumen o se compran esos productos. Antes se fabricaba para satisfacer las necesidades naturales de las personas, ahora para satisfacer las necesidades emocionales, psicológicas. Aquí entra a jugar la publicidad, ya que todo lo que se produce debe ser vendido, y para ello se encarga de crear esas necesidades.
Resumen

La publicidad es una actividad muy importante en el trabajo de mercadeo. A través de ella se logra crear posicionamiento a las marcas en la mente de los consumidores. ¿Cómo es posible que la mente acepte el posicionamiento? ¿Por qué funciona la publicidad? ¿Qué efectos tiene ésta en el aprendizaje y posterior conducta de los consumidores?

La publicidad es creadora de mitos, pero con una característica diferente: los mitos nos hablan del pasado, pero la publicidad nos crea mitos hacia el futuro. Las marcas no marcan a los productos, marcan al consumidor. En este ensayo se hace una reflexión al tema de la publicidad, pero también se hace una revisión de las técnicas usadas por los publicistas, para lograr penetrar la mente de los consumidores y lograr el consumo, como una manera de diferenciar a las personas y que se vuelve en un elemento de exclusión en nuestra sociedad.

*1 Reyes Mate. (2009). Medianoche en la historia. Editorial Trota, Segunda Edición Madrid, p.39. 


\begin{abstract}
¿Cómo es posible que una mercancía que es el resultado de un proceso de producción se nos pueda presentar con autoridad propia como creadora y dadora de sueños? Más aún, esos productos que se nos presentan como novedosos tienen la capacidad de transformarse en otros mejores para aumentar la felicidad de aquellos que los consumen. Reyes Mate dice que esa autopoiesis le da a la mercancía la autoridad de presentarse ante el consumidor como ideal de felicidad, más aún, como realización de la felicidad? Este fenómeno solamente ha sido posible gracias a la publicidad que nos crea sueños, que nos ensueña con sus mensajes cual si fueran canto de Sirenas, que nos embrujan y nos embrutecen hasta que aparece el próximo producto con mucho más encanto que el anterior. Parafraseando a Ellacuría uno podría preguntarse, ¿Qué tiene la mente que acepta con facilidad todos estos mensajes de la publicidad? ¿Por qué la inteligencia posibilita aceptar, sin más, toda esta comunicación publicitaria?3
\end{abstract}

En todo el engranaje de la técnica de producción, la publicidad necesariamente se ha vuelto parte esencial, ya que nadie pensaría en montar un proceso de producción sin incluir la publicidad como algo vital dentro de lo que se llama el mercadeo. Pero resulta que en esa espiral, también el consumidor se vuelve parte de todo ese engranaje, ya que se produce para consumidores target ${ }^{4}$ y por tanto ésta nos arrastra a formar parte del engranaje. No imaginamos la felicidad completa, para nosotros y nuestras familias y conocidos, sin los productos que se nos ofrecen a través de los mensajes publicitarios. Huir de sus influjos, solamente sería con el consejo de la hechicera a Ulises: taponarse los oídos y pasar delante de sus llamados; o en su mejor caso, atarnos al mástil de nuestra realidad y aunque sus sonidos son tan agradables no dejar que el nudo se desate para evitar la compulsión.

Como la verdad nadie la posee completamente y la felicidad la obtenemos de donde la podemos sacar, principalmente cuando estamos navegando por los mares de nuestras creencias que son tan, pero tan cuestionables, pero tan nuestras a la vez, por eso este ensayo es una reflexión crítica, pero también es un análisis de la técnica publicitaria y por lo tanto, trataré de revisar a la luz de las herramientas mercadológicas y de comunicación porqué es tan efectivo el mensaje publicitario. Pero, también, a través del desarrollo de este trabajo pretendo demostrar cómo la publicidad retoma el mito como proceso de aprendizaje. Uno de los objetivos del mito en la antigüedad era transmitir aprendizaje y legitimar conductas. Mircea Eliade captura mejor este concepto señalando que el mito debe verse en "el sentido de proporcionar modelos a la conducta humana y conferir por eso mismo significación y valor a la existencia" 5 . A través de la publicidad se da aprendizaje a los receptores para modificar conductas, y lograr que de esa manera adopten posturas deseables de acuerdo a los objetivos de la misma. Cuando menciono postura me refiero a actitud, ya que la actitud más radical que puede tomar el receptor de la publicidad es modificar sus patrones de conducta orientados hacia algo específico. Los medios de comunicación, básicamente, producen tres tipos de discursos: el discurso publicitario, el discurso periodístico y el discurso lúdico. En este ensayo me ocuparé del discurso publicitario y de la televisión como medio primario.

\section{El discurso publicitario}

La publicidad debe estudiarse como una propuesta discursiva que forma parte de un proyecto cultural y por tanto tiene pretensiones hegemonicas en tanto tratará de legitimar un particular tipo de subjetividad; ${ }^{6}$ por tanto los medios que se utilizan para ejecutarla también se vuelven hegemónicos. Desde esta perspectiva el discurso publicitario de la televisión es igualmente hegemónico.

Una faceta importante de la televisión es la capacidad de difundir mensajes comerciales. Esto ha sido bien aprovechado por los fabricantes de grandes marcas que utilizan como medio primario este vehículo, para posicionar en la mente de los consumidores toda una gama de productos que "nos proponen vivir la vida como una película, en la cual cada uno puede o debe ser estrella"7. Una de las tareas principales de la publicidad (sino la más importante), es crear posicionamiento 8 Éste, para decirlo de una manera simple pero válida, es lo que los consumidores piensan de una marca o un producto, un servicio, una institución, un partido político o de una persona y que constituye la principal diferencia que existe entre esa marca y su competencia.

Una marca/producto es un conjunto de características tangibles e intangibles que satisfacen las necesidades de los consumidores. Bajo este concepto de producto, lo que los consumidores aprecian de él son las características que perciben de éste. La tarea entonces de la publicidad es que esas características que tiene el producto lleguen de una manera clara y penetren la mente de los consumidores. Hablando metafóricamente, en el mercado no hay guerra de productos, sino guerra de percepciones y por tanto es una batalla por ganar la mente de los consumidores?

Cuando las características de los productos son claras para el consumidor, entonces se puede decir que hay posicionamiento de la marca/producto. La marca/producto se vuelve amigable para el consumidor y se posiciona en la mente como la primera opción, lo que en lenguaje publicitario se conoce como top of mind.

El posicionamiento es una estrategia de comunicación mercadológica en tanto que trabaja para el largo plazo y por eso la publicidad trabaja igual. El concepto de posicionamiento es relativamente nuevo en la jerga de mercadeo, como lo es este el mismo concepto.

*2 Reyes Mate. (2009). Medianoche en la historia. Editorial Trota, Segunda Edición Madrid, p. 40.

*3 Ellacuría, I. (2009). Cursos Universitarios. UCA Editores, El Salvador. p. 328.

*4 Target: conjunto de personas con ciertas características en común al que se dirige una acción publicitaria.

*5 Eliade, M. (1991). Mito y realidad. Editorial Labor. S.A. Barcelona.

*6 Colón Zayas, E. (2001). Publicidad y hegemonía. Matrices discursivas. Grupo Editorial Norma, Colombia. p. 11.

*7 Rincón, O. (2006). Narrativas mediáticas. De cómo se cuenta la sociedad del entretenimiento. Barcelona: Gedisa. Págs. 17-85.

$\star 8$ Blacwell, R., Miniard, P. Angel, J. (2002). 487-494.

*9 Ries, Al y Trout, Jack, (1993). p. 25 
Se comenzó a hablar de posicionamiento, aplicado al mercadeo de los productos, en la década de los años sesenta del siglo pasado, y no fue hasta el año 1971, cuando Jack Trout lo acuñó en un artículo titulado "Posicionamiento es un juego que las personas practican en el mercado actual del yo-también" y publicado en la revista Industrial Marketing 10 Cuando se escribió ese artículo, toda la argumentación del tema posicionamiento pasó inadvertido y, de hecho, siguieron muchos artículos y muchas conferencias de Jack Trout y nada sucedió. Fue hasta el año 1981 que junto a otro académico, Al Ries, escribieron el clásico libro "El posicionamiento, la batalla por la mente", donde el tema se volvió una herramienta poderosa en mercadeo y se comenzó a construir toda una serie de técnicas para darle fijeza a este concepto. Actualmente, existen procesos muy elaborados para crear posicionamiento y ganar la mente de los consumidores. Todo esto aprovechando los avances que se dieron en las diferentes ciencias sociales, tales como la psicología y la sociología, disciplinas que han aportado mucho al mercadeo.

Aunque el concepto llegó a hurtadillas, actualmente parece tan fresco y joven que se le sigue utilizando como una herramienta poderosa para vender los productos en el mercado. Los autores basaron el concepto de posicionamiento, analizando las limitaciones que tiene la mente humana y estudiaron básicamente seis temas sobre la mente: las mentes ya no aguantan, las mentes son limitadas, las mentes odian la confusión, las mentes son inseguras, las mentes no cambian y las mentes pueden perder su enfoque ${ }^{11}$.

\section{La publicidad como proceso de aprendizaje y su impacto en la cultura}

Así como es posible ganar la mente de los consumidores para un producto, también se hace a través de la publicidad, para cambiar la mente de las personas hacia otros propósitos y por eso es importante analizarlo desde la perspectiva de la comunicación y la cultura, ya que a través de la publicidad se pueden cambiar patrones culturales que tienen incidencia clara en las actitudes de todo un conglomerado.

La etimología de la palabra publicidad en el idioma inglés tiene más fuerza que en el idioma español. En inglés, la palabra "advertising" se deriva del latín "advertere", que literalmente significa "mover la mente hacia" y eso es precisamente lo que hacen los anuncios publicitarios, mueven la mente del consumidor hacia objetivos bien definidos previamente y que se dejan plasmados en el documento, que en publicidad se conoce como la estrategia creativa. De esta misma raíz latina deriva la palabra advertorial, que según Russel y Lane, se ha vuelto una preocupación ética de muchos ejecutivos de los medios, porque el advertorial es un espacio que en vez de presentar productos o servicios, se presentan ideas y hay mucho cuestionamiento sobre posibles finas violaciones a la libertad de prensal? Es obvio que para lograr que los consumidores "muevan la mente hacia" donde quieren o desean los publicistas se necesita ayudar a los consumidores a recordar. ¿Cómo se logra este proceso de "recordar"? Básicamente los mercadólogos han recurrido al aporte que ha dado la psicología sobre el aprendizaje. Tanto el condicionamiento clásico de Pavlov, como el condicionamiento operante de Skinner con sus reforzamientos positivos y negativos ${ }^{13}$, las cuales han sido herramientas poderosas en manos de los mercadólogos para lograr sus objetivos de dar aprendizaje a los consumidores.

\section{Aprendizaje cognoscitivo}

El aprendizaje es un cambio relativamente permanente producido por la experiencial4 Cuando es un proceso múltiple e interactivo que involucra todas las funciones mentales - a saber percepción, memoria, pensamiento, lenguaje, creatividad, motivación, emoción - se le llama aprendizaje cognitivo o cognoscitivo. La capacidad cognitiva y la distinción entre memoria de corto plazo (donde ocurre el pensamiento y la interpretación) y de largo plazo (el almacén mental donde reside el conocimiento) es importante para entender lo cognitivo del aprendizaje.

El aprendizaje cognoscitivo se produce cuando la información que se procesa en la memoria de corto plazo queda almacenada en la memoria de largo plazo. ${ }^{15}$ Todo el proceso involucra repaso (repetición), grado de relación, motivación, etc., y allí es donde interviene la publicidad para dar todos estos refuerzos.

Resumiendo, y parafraseando a Jesús Martín-Barbero (aunque él se refiere en conjunto a los medios de comunicación), todo esto se elabora en el transcurso del proceso de recepción, reconocimiento y apropiación. 16 Sabemos que todo discurso es intencional, hegemónico, que está buscando un posicionamiento, ya sea posición de reconocimiento social, económico o político, y el accionar de la publicidad no es la excepción. Una vez se produce el posicionamiento, la publicidad puede cambiar actitudes, crear estereotipos que inciden en las conductas de las personas y por tanto en sus patrones culturales.

\section{El mito como interpretación de la realidad}

Resulta interesante que el semiólogo Roland Barthes en su libro Mitologías, se ocupa del anuncio publicitario como mito moderno. Ya lo decía Barthes, el mito es un habla, constituye un sistema de comunicación, un mensaje17 El término es de origen griego y significa literalmente: "palabra explicada, discurso o narración".18 Esta definición implica algunas cosas: primero, a través de este se pueden explicar relaciones sociales, es decir lo que hace posible al hombre encontrar su lugar en el mundo y fortalecer sus lazos con las demás personas; sequndo y más concluyente aún, a través del mito el individuo puede sustentar, legitimar para sí un sistema de valores que le den sentido a su vida. Los valores de una persona tienen su origen en sus creencias, aunque no pueda comprobarlas 19
*10 Trout \& Rivkin. (1996). El poder de lo simple. Serie McGraw-Hill de Management. Coordinador José Carlos Jarillo Mossi Universidad de Ginebra (Suiza).

*11 Ibíd. Págs. 9-12.

*12 Russell, T. y Lane, R. (2001). Publicidad. Decimocuarta Edición Printece Hall, México.Págs. 696-697

*13 Felman, Robert S. (2002). Págs. 189-196.
*14 Ibíd. p. 647

*15 Martín-Barbero, J. (1998). De los medios a las mediaciones. Bogotá: Convenio Andrés Bello. Prefacio.

*16 Pistas para entrever de los medios a las mediaciones. Págs. $x i-x x x i$

*17 R Barthes, R (1999), p. 118

*18 Bohmer, O. (1997). p. 109

*19 Feldman, Robert S. (2002). Págs 187-223. 
En ese sentido, el filósofo alemán, Christoph Jamme dice: "el mito deja de ser un ropaje (alegórico) para revestir determinada verdad y se convierte en procedimiento al servicio de la interpretación de la realidad"20 Jamme lo interpreta como un sistema de experiencias numinosas, es decir algo divino o religioso y por ello en el mito se desconoce los hechos puros y no distingue entre sujeto y objeto, entre lo ideal y lo material, entre nombre y cosa, entre posibilidad y sueño. 21 La verdad en el mito no es lógica y por lo tanto es esencialmente mágica. En eso radica su necesidad porque el hombre no podría existir humanamente sin legitimación y el mito le da esa posibilidad.

El mito se pierde en el tiempo ya que siempre fue una narración verbal y está, en su origen, vinculada a culturas que carecían de escritura. Zubiri plantea que el hombre en la actitud mítica tiene una conciencia mítica. Se enfrenta a las cosas, pero éstas no son simples cosas - poderes adversos o favorables dice Zubiri - Esta es una actitud radical, en cuanto es la primera actitud hacia las cosas. En ese mundo no es el hombre el que hace al mito, sino que el mito crea al hombre. En la actitud mítica no es que el hombre simplemente deja volar su imaginación: el hombre hace funcionar su imaginación porque existe en una actitud mítica. El mito es realidad mientras se está en la actitud mítica, sólo es verdadero o falso visto desde la actitud teórica22

El mito literario lo encontramos en una época tardía, como se puede ver en Homero y Hesíodo, alrededor del siglo sexto antes de Cristo. Los griegos aceptan el mito para darle interpretación a sus relaciones sociales, a la tradición y costumbre y también como un método para legitimar modos de actuar. En la sociedad griega el mito y el pensamiento racional caminaban en una misma senda y era una forma de trascender la realidad social, de representarla, categorizarla y fundamentarla23. En ese sentido, los griegos intentan comprender su mundo, darle sentido y legitimarlo a través del mito. El mito de la mujer, por ejemplo, queda legitimado cuando Zeus, enojado por el robo del fuego por Prometeo, castiga a los hombres enviándoles un mal: Pandora, la mujer24 Según Hesíodo, ésta tiene cualidades que le dieron los dioses: una imagen semejante a una virgen venerable, irresistible sensualidad, vocación de los cuidados de hogar, mujer voluble, mentirosa, pérfida, halagüeña, impúdica, etc. Este relato de Los trabajos y los días de Hesíodo muestra claramente como el concepto de mujer, se ve deformado, se muestra estereotipado y hasta el día de hoy esta explicación parece bastante normal y es aceptada por la cultura moderna, especialmente la cultura occidental, que unido al relato de la creación del Génesis, convirtieron a la mujer en algo como un mal inevitable. Esto es un ejemplo claro de cómo a través del mito se busca legitimar conductas, en este caso muy desfavorable a la mujer ya que la reproducción de estos mitos legitimó que la mujer, a través de la historia, ocupase un lugar secundario e inferior al hombre y es un pensamiento y una creencia perversa que hasta nuestra época se sigue reproduciendo. El mito nos persigue.

Está claro que el mito explica y legitima conductas para que las sociedades puedan funcionar. Esto no significa que todo lo explicado y legitimado por el mito sea cierto o sea correcto, pero es una manera de explicarlo y es una forma de funcionar imprescindible en cualquier sociedad. Los publicistas y mercadólogos conocen esto y van a utilizar los mitos como un proceso de aprendizaje para los consumidores.

\section{La mercancía como elemento jerarquizador del estatus social}

En la parte introductoria del libro La sociedad de consumo, sus mitos, sus estructuras de Jean Baudrillard, se afirma que "el consumo se basa en una carencia que es irreprimible" 25 Normalmente el consumo se explica como consecuencia de una necesidad y en todo caso la publicidad estaría para informar mejor cómo se pueda satisfacer esa necesidad. El consumo no es mas que un fragmento de una vasta ciencia de los signos que Saussure postuló bajo el nombre de semiología. Saussure distinguió entre lengua y habla considerando la lengua como un sistema de signos independiente del uso que de él hace el individuo. Los signos bajo la semiología tienen un significado y un significante 26 Así, todo sistema de intercambio es ante todo un sistema de signos y, en base a esto, se puede entender la lógica de la sociedad de consumo y como ésta funciona. Como esto es comunicación, es logico que se pueda codificar $y$, por supuesto, también decodificar, y desde esta perspectiva, Baudrillard desarrolla un análisis del consumo como una manipulación sistemática de signos. Desde el lado de mercadeo, cuando se estudia por qué compra la gente, es decir la conducta del consumidor. Se sabe que las personas toman su decisión de comprar - o no comprar algo - primero como una decisión emocional que luego justifican racionalmente 2 ? En esta decisión emocional, el significante y el significado, es decir las aspiraciones simbólicas que el signo pueda tener es determinante. Todo esto obedece a la lógica del sistema de producción capitalista, donde el énfasis no es lo que la sociedad está dispuesta a consumir, sino que el modelo está centrado desde el lado de la producción, es decir se produce más de lo que se necesita y por tanto el modelo viola la más elemental de las leyes económicas que es igualar la oferta con la demanda de los bienes y en ese sentido el modelo se carga al lado del fabricante/vendedor. Para ello se necesita que las personas consuman, sin que exista una verdadera necesidad de hacerlo y esto se logra a través de la mercancía en tanto que signo. Es por eso que el signo mercancía se vuelve un elemento jerarquizador de estatus social, es decir es un proceso de clasificación y diferenciación. Una nueva polarización, dirá Bauman, porque el consumo lejos de homogenizar la condición humana (...) tiende a polarizarla28

*20 Jamme, C. (1999). p. 17.

*21 Ibíd. p. 209.

*22 Zubiri, X. El despertar del hombre a la actitud teorética. Inédito de X. Zubiri. Forma parte del volumen III de los cursos Universitarios a fecha del 27 de enero de 2011. Editor Manuel Mazón.En imprenta.

*23 Gómez Rodríguez, A. (2004). La extirpe maldita. La construcción científica de lo femenino. Minerva ediciones, Madrid. Pág. 36.

*24 Hesíodo. Los trabajos y los días Texto clásico de libre circulación en la web, bajado de http://www.imperivm.org/cont/textos/txt/hesiodo_los-trabajos-y-los-dias.html. Sitio visitado el 4 de julio de 2014.

*25 Introducción de Luis Enrique Alonso al libro La Sociedad de Consumo. Sus Mitos, Sus Estructuras, de Jean Baudrillard. Siglo XXI de España. Págs. XxxV

$\star 26$ Barthes, R. (1999). Mitologías. Decimosegunda edición, Siglo Veintiuno Editores, S.A. de C.V. Madrid, México. Págs. 179-122.

*27 Blacwell, R., Miniard, P., Ángel, J. (2002). Comportamiento del consumidor. 9a. edición. Thomson Learning. Págs. 160-165.

*28 Bauman, Z. (2001). La globalización. Consecuencias humanas. Fondo de cultura Económica, México. Págs. 28-38. 


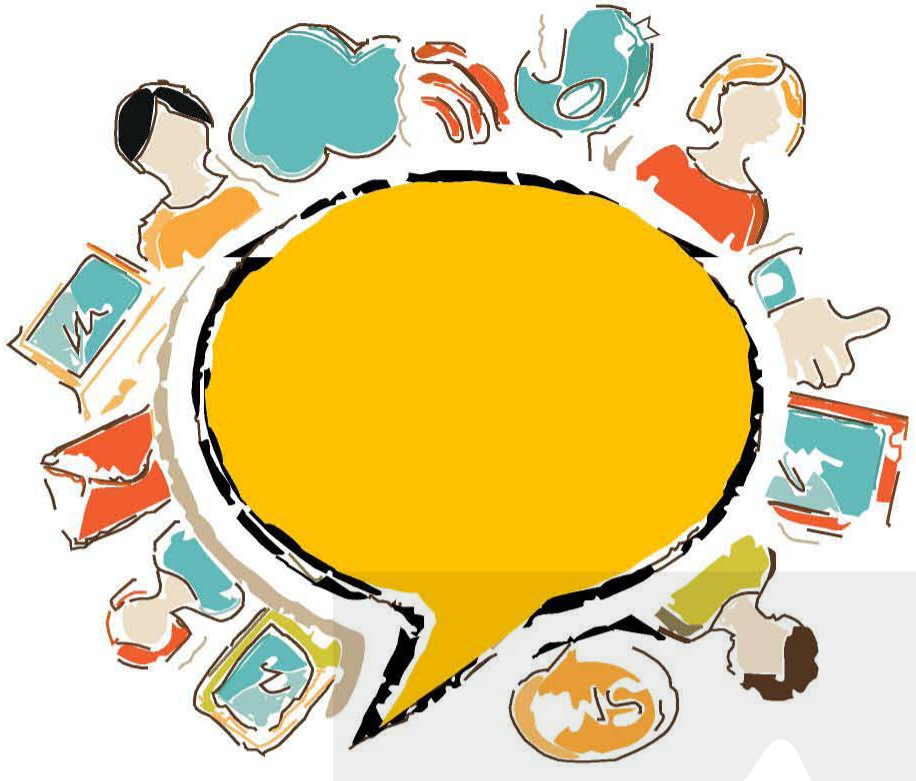

Desde esta perspectiva, el consumo se vuelve como una lógica diferenciadora y de dominio que busca estatus y poder. Es por lo tanto el código que regula la producción simbólica y donde se puede dar la clasificación y diferenciación de los seres humanos porque se jerarquiza a los grupos sociales y hace posible las estructuras de desigualdad y dominio. La Marca de un producto no marca al producto, marca al consumidor, como miembro del grupo de consumidores de la marca? Las marcas, entonces están hechas como un medio para crear desigualdad y consumir, es por lo tanto, una forma positiva de desigualdad, pero además es una inspiración continuada e ilusoria, porque nunca produce satisfacción. Es un mito dice Baudrillard:

"El consumo es un mito, es un relato de la sociedad contemporánea sobre ella misma, es la forma en la que nuestra sociedad se habla. [...] Nuestra sociedad se piensa y se habla como sociedad de consumo. Al menos mientras consume, se consume como idea de sociedad de consumo"30

Y ¿Cuál es el canto triunfal de esta idea? La publicidad, termina diciendo Baudrillard. Es ese sentido que la publicidad juega un rol determinante en perpetuar el mito del consumo; la publicidad juega su rol hegemónico en el Mass Marketing. Ya en 1954 Herbert Marcuse, que era miembro de la Escuela de Frankfurt, afirmó que se puede distinguir entre necesidades verdaderas y falsas. Estas últimas son aquellas que intereses sociales particulares imponen al individuo para su represión: las necesidades que perpetúan el esfuerzo, la agresividad, la miseria y la injusticia3̣! Estas necesidades, como es de suponer, se perpetúan con el uso de los medios masivos (Mass Media), con la publicidad que a través del uso del mito es capaz de mover la mente de las personas hacia un fin preconcebido.

\section{La publicidad y los mitos}

La publicidad ha jugado un papel importante en lo que Omar Rincón llama las culturas mediáticas. La publicidad ha generalizado en la sociedad un gusto, "una sensación individual de placer...que expresa la sensación de pertenecer a algo y compartirlo"3 2 La publicidad es creadora de mitos, pero con una característica diferente. Normalmente los mitos tienen arraigos lejanos en el tiempo; se pueden rastrear ciertos mitos y ver cómo ha llegado hasta nosotros casi intacta su esencia, como en el caso que ejemplificamos de la mujer. De alguna manera nos influencia en nuestros patrones culturales y nuestra manera de pensar, es decir, el valor y el modelo que transmiten vienen del pasado. La antigüedad nos sigue susurrando al oído. Por el contrario, los medios y la publicidad nos construyen mitos hacia el futuro. El pasado se nos presenta como algo oscuro y negativo que ya no debemos voltear a ver. El futuro es la luz, es el oriente (lo que nos orienta) que debe guiarnos en esta posmodernidad. El peregrinaje ha quedado atrás, "las huellas en la arena se borraron"33 Ahora tenemos a los medios y a la publicidad que nos construyen los nuevos mitos que debemos recorrer hacia adelante.

La lógica del consumo está asociado a los grandes centros de compra (mall). Estos grandes centros comerciales, en El Salvador, son nuestros mitos futuros y que son fijados por medio de la publicidad. Como menciona Bauman en el texto citado anteriormente (en tanto que paseante, jugador, vagabundos o simplemente turistas) el mito del Mall ya es una realidad hacia el futuro y estos lugares son los ámbitos predilectos de la vida urbana. Aunque hay grandes mayorías que no tienen acceso a dichos espacios. Sin embargo la publicidad los motiva, los pellizca para que sean posmodernos como lo son todos.

Por otro lado, la publicidad nos construye mitos ad-hoc, según sean nuestros gustos. Se nos ofrece hacia el futuro el mito de la limpieza, el mito de la blancura, el mito de lo erótico y sensual, los mitos musicales, etc., es decir hay para que cada uno escoja todo a su medida y hacer de esta vida un deleite y todo gracias a la cultura de la imagen. La publicidad nos ayuda a tener esa conciencia.

*29 Véase el estudio Introductorio que hace Luis Enrique Alonso, de la Universidad Autónoma de Madrid, al libro La Sociedad de Consumo. Sus Mitos, Sus Estructuras, de Jean Baudrillard. (2009). Siglo XXI de España, Editores, S.A. XLIII. *30 Baudrillard, J. (2009). La Sociedad de Consumo. Sus Mitos, Sus Estructuras, de Jean Baudrillard. Siglo XXI de España Editores, S.A. 2009. Págs. 247-248.

*31 Marcuse, H. (1993). El hombre unidimensional. Editorial Planeta Argentina, S. A. Buenos Aires Pág. 35.

*32 Rincón, O. (2006). Narrativas mediáticas. De cómo se cuenta la sociedad del entretenimiento. Barcelona:Gedisa. Págs. 17-85.

*33 Ver estudio de Bauman en De peregrino a turista, o una breve historia de la identidad. En Stuart Hall y Paul du Gay (comps.). (2003). Cuestiones de identidad cultural. Buenos Aires: Amorrortu. 


\section{Mito e ideología}

A través de la publicidad, se crea el mito del macho, del hombre conquistador, de la mujer que es amada como una virgen, del hombre que tiene poder a través de sus patrones de consumo, etc. La pregunta es: ¿cómo se puede lograr esto? ¿Qué tiene la inteligencia que acepta fácilmente estos patrones de conducta? Porque esto es, sin duda, un asunto de la inteligencia humana. Ya Ellacuría se hacía estas preguntas cuando disertaba acerca de las ideologías y porque, pensándolo bien, la ideología y el mito están en la inteligencia y en la capacidad de lo inteligible del ser humano en aceptarlas, vivirlas y reproducirlas $34 \mathrm{Mi}$ tesis es que mito e ideología, convergen en un punto crítico: me explican el mundo y mi relación con él. En ese sentido se puede abordar el mito como un hecho ideológico, porque es un fenómeno social y de comunicación. El concepto ideología normalmente está cargado de una connotación negativa o despectiva, decía Ellacuría, ya que se emplea por lo general para referirse a las ideas políticas de los "otros" y que siempre será diferente del punto de vista de "uno" y por lo tanto se juzgará como algo irracional e inconsistente. Sin entrar en el tema ontológico de ideología, quiero referirme a ese conjunto sistemático que forma una cosmovisión y unas creencias que definen la forma de estar en el mundo, que le dan sentido a la vida en sociedad y que es lo que él llama ideología35 Es necesario ese conjunto de conocimiento que valore e interprete la relación del individuo con la sociedad y consigo mismo y eso es la ideología, pero también es el mito. Podría entonces hablar de los mitos ideológicos o de la ideología mítica, que para este caso da igual porque ambos me dan esa explicación. Este tema no es en balde, más bien lo retomo, porque me permite explicar el mito publicitario y aplicarle la metodología que Ellacuría propone para las ideologías. El expone que el proceso de ideologización se fundamenta en la abstracción histórica que incluye: hacer de lo histórico algo natural, es decir que las personas piensen que los hechos han sido fruto de acciones humanas, algo que así debe ser, porque es un contrato social o que Dios así lo quiere, etc. Además se debe hacer que se acepte sin comprobación histórica que lo que se da en la lógica ideal corresponde con la realidad 36

Partiendo de esta propuesta, puedo entender mejor el proceso publicitario como un proceso ideológico-mítico que de alguna manera me explica mis ansiedades hacia el futuro.

Los publicistas trabajan esta comunicación a través de lo que se conoce como la estrategia creativa. La estrategia creativa es un formato formal que tiene dos secciones. La primera parte es donde se define los objetivos de la comunicación publicitaria, principalmente se define el consumidor target, es decir a qué segmentos de la población irá dirigido el mensaje publicitario y cuál es el posicionamiento que se le quiere dar al mensaje. Aquí es donde está la clave: el posicionamiento permitirá penetrar la mente del consumidor y que éste acepte en el subconsciente que lo mostrado en el mensaje publicitario, de alguna manera tiene su referente en la realidad. El mito aquí opera hacia el futuro, es decir lo que promete al potencial consumidor qué hará en su vida al usar o consumir este producto. La segunda parte de la estrategia creativa es la estructura del mensaje, la manera de presentar el mensaje, es decir, las promesas, el tono, el modo, la forma, los slogans, etc. Este soporte es estratégico, porque determinará que el posicionamiento sea bien aceptado. De lo que se trata no es que los receptores racionalicen el mensaje, eso no es lo importante; lo que se pretende es que ellos acepten el mensaje desde las instancias mitológicas o mitogénicas para su interpretación.

\section{El simbolismo de los mensajes publicitarios: hasta los ángeles caerán 37}

Si nos detenemos en este comercial es claramente una invitación hacia el futuro de una vida de placer para el hombre, es decir el mito del conquistador. En el comercial se observa cómo comienzan a caer del cielo muchos ángeles atraídos por la belleza y por la limpieza que un hombre ofrece. La gente se queda perpleja ante un hecho tan insólito, que no dan cuenta de este evento. Los ángeles, representados por bellas mujeres deciden despojarse de su poder angelical y destruyen el símbolo que les da ese poder con tal de estar cerca y entregarse al hombre que les ha cautivado con su frescura y su fragancia. Al analizar más de cerca este comercial se puede detectar su estrategia creativa: en primer lugar están bien identificados los públicos objetivos (targets) y claramente está orientado primariamente a hombre de 18 a 25 años de edad y un target secundario son mujeres que alcanzan las mismas edades. El objetivo del comercial es que el nuevo Axe Excite ofrece un mundo lleno de misterio y de sorpresas para aquellos hombres que se atrevan. El posicionamiento se compone de una promesa básica y es la frase hasta los ángeles caerán, denotando que al utilizar este producto no habrá nada que se resista incluyendo a las mujeres más preciosas. El razonamiento a esta promesa básica es la forma que se observa de la caída de los ángeles, mujeres irresistibles. También hay una promesa secundaria que ofrece que con Axe Excite la limpieza está garantizada, es decir siempre el hombre lo evidenciará a través de olores que son agradables e irresistibles para las mujeres. El tono es serio y convincente; la manera es demostrativa a tal grado que al finalizar el comercial, el hombre prueba nuevamente su Axe Excite y se ve como comienzan a caer plumas de ángeles. El slogan es el mismo posicionamiento, hasta los ángeles caerán. Jingles no hay, pero la música está acorde al target del comercial. El comercial es impecable en su realización y causa buena impresión; además gusta y no molesta verlo varias veces por todo el glamur de los ángeles. En este comercial también se detecta el aspecto míticoreligioso. La aparición de ángeles ya le dan esta justificación y como complemento subliminal la música de fondo que es como coros entonando música sacra. Este es un ejemplo de cómo se utiliza la publicidad para crear mitos. En el medio se pueden ver comerciales de este mismo tipo, que por razones de espacio y tiempo no es posible comentarlos aquí 38

*34 Ellacuría, I. (2009). Cursos Universitarios. UCA Editores, El Salvador. Pág. 328.

*35 Ibíd. Pág. 368.

*36 Ibíd. Pág. 375

*37 En base a una campaña publicitaria de una marca de desodorantes para hombres.

Web: https://www.youtube.com/watch?v=aTOs-stqaEE. Consultada el 8 de julio de 2014

*38 Dejó en la bibliografía un enlace de un comercial de Testitón, que ya no me fue posible analizar aquí, pero que igual se le puede aplicar el análisis de la estrategia creativa. 
Conclusiones

A través de este breve ensayo es posible observar la presencia de determinados mitos en el entorno de los anuncios publicitarios. Por supuesto, el objetivo de este trabajo era hacer un acercamiento al mito desde las estructuras lingüísticas utilizadas en la comunicación publicitaria. Este acercamiento, a mi juicio, se ha logrado. Sin embargo, todavía quedan muchas interrogantes para que en futuras investigaciones se puedan abordar. Aquí hemos investigado, desde la perspectiva teórica del análisis estructuralista saussureano, pero todavía hay preguntas desde el lado de la recepción de los mensajes publicitarios, que en este ensayo no se alcanzó a analizar. Queda abierto, pues, este reto para futuras investigaciones.

En una entrevista hecha a Jesús Martín-Barbero dijo: "los contenidos de la mayoría de los medios de comunicación, se ha hecho cada vez más manifiesta, más descarada, más desvergonzada" 39 Desde mi punto de vista, en El Salvador, la publicidad es generadora de exclusión. Por un lado, se nos provoca, se nos persuade a consumir. Como dice el Dr. García Canclini, y cito literalmente, "si se quiere entender el mundo en que vives, (...) debes relacionar las tiendas de Nueva York, y México, de Buenos Aires y de Paris, con las fábrica de Yakarta y de El Salvador" (García Canclini. 2002). Este país, inserto en el concierto mundial de la globalización y como punto medular el neoliberalismo que cada día se va asentando de una manera dramática, va, como dice una canción popular "como patines cuesta abajo y solo esperando el golpe". La publicidad nos anima a consumir lo que hay en esas tiendas "para ser algo", pero resulta que la mayoría de la población apenas tiene algo. Quizás todavía un poco de dignidad, porque si va un día a comer junto a su familia al famoso "Pollo Campero", tal vez se gaste lo que ganó en toda una semana de trabajo en las maquilas. Todo el despliegue de tanta tecnología de los medios no debería servir para generar sociedades excluyentes, pero bien lo dice Martín-Barbero en la misma entrevista mencionada arriba: "hay que entender que no es la tecnología por sí misma la que excluye a la gente sino una sociedad excluyente que usa a la tecnología para excluir".

¿Qué hay detrás de la publicidad? Los verdaderos intereses de los productores de imagen se ocultan de una manera muy sutil y refinada y es difícil descubrirlos. Los productores y "creativos" publicitarios son personas comunes y corrientes que juegan a un juego, su juego, sus intimidades reflejadas a través de la industria de la imagen. Un amigo mío, dueño de una agencia de publicidad y productor de comerciales me decía hace ya varios años, que los "creativos" de las agencias de publicidad son personas "especiales", tienen que mostrar dominio de "pensamiento periférico", es decir, tiene que decir, mostrar las cosas no de una manera convencional, su pensamiento "periférico" lo demuestra en la creatividad para expresar los mensajes.

En todo caso, el lado excluyente de la publicidad no es por la publicidad en sí misma, sino que lo que excluye a la gente, parafraseando a Martín-Barbero: es una sociedad excluyente que usa la publicidad para excluir. Sólo nos queda taponarnos los oídos y atarnos al mástil del navío de nuestra realidad para que los cantos de sirena de la publicidad no nos embrutezcan. ¡Difícil, pero no imposible!

\section{Bibliografía}

Barthes, R. (1999). Mitologías. Decimosegunda edición. Siglo Veintiuno Editores, S.A. de C.V. México.

Baudrillard, J. (2009). La Sociedad de Consumo. Sus Mitos, Sus Estructuras. Siglo XXI de España Editores, S.A.

Bauman Z (2001) La globalización. Consecuencias humanas. Fondo de cultura Económica México

Bauman, Z. (2003). De peregrino a turista, o una breve historia de la identidad. En Stuart Hall y Paul du Gay (comps.). Cuestiones de identidad cultural. Buenos Aires: Amorrortu.

Blacwell, R., Miniard, P., Ángel, J. (2002). Comportamiento del consumidor. 9a. edición. Thomson Learning. Bohmer O (1997) Diccionario de Sofía Primera edición. Ediciones B Barcelona España.

Colón Zayas, E. (2001). Publicidad y hegemonía. Matrices discursivas. Grupo Editorial Norma, Colombia. Eliade, M. (1991). Mito y realidad. Editorial Labor, S.A., Barcelona

Ellacuría, I. (2009). Cursos Universitarios. UCA Editores, El Salvador.

Gómez Rodríguez, A. (2004). La extirpe maldita La construcción científica de lo femenino. Minerva ediciones, Madrid.

Felman, Robert S. (2002). Psicología. McGraw-Hill. 4 a edición.

Jamme, C. (1999). Introducción a la filosofía del mito en la época moderna y contemporánea. Ediciones Paidós Ibérica, S.A., Barcelona, España.

Marcuse, H. (1993). El hombre unidimensional. Editorial Planeta Argentina, S. A. Buenos Aires.

Martín-Barbero, J. (1998). De los medios a las mediaciones. Bogotá: Convenio Andrés Bello. Prefacio. Pistas para entrever de los medios a las mediaciones. Págs. xi-xxxi

Reyes Mate, Medianoche en la historia. Editorial Trota, Segunda Edición Madrid, 2009

Ries, Al y Trout, Jack, (1993). Las 22 leyes inmutables del Marketing. México, McGraw-Hill

Ries, Al y Trout, Jack (1981). El posicionamiento, la batalla por la mente. McGraw-Hill.

Rincón, O. (2006). Narrativas mediaticas. De cómo se cuenta la sociedad del entretenimiento. Barcelona: Gedisa.

Roncagliolo, R. (2006). Espacios públicos y políticas culturales en Perú. En Néstor García Canclini (coord.)

Reabrir espacios públicos. Políticas culturales y ciudadanía México D.F.

Russell, T. y Lane, R. (2001). Publicidad. Decimocuarta Edición, Printece Hall, México. Trout, J. y Rivkin, S. (1996). El Nuevo posicionamiento. McGraw-Hill.

Warnier, Jean-Pierre. (2002). Las culturas y la tradición. La mundialización de la cultura. Barcelona: Gedisa.

Zubiri, X. El despertar del hombre a la actitud teorética. Inédito de X. Zubiri. Forma parte del volumen III de los cursos Universitarios a fecha del 27 de enero de 2011. Editor Manuel Mazón. En imprenta. Web Visitada

Comercial Hasta los ángeles caerán. Visitado en https://www.youtube.com/watch?v=aTOs-stqaEE. Consultado el 8 de julio de 2014. Comercial Testitón.

http://www.youtube.com/watch?v=DmUXvnSClUk. Sitio visitado el 8 de julio de 2014.

Hesíodo. Los trabajos y los días Texto clásico de libre circulación en la web, bajado de http://www.imperivm org/cont/textos/txt/hesiodo_los-trabajos-y-los-dias.html. Sitio visitado el 4 de julio de 2014.

*39 Entrevista por la periodista María Clara Lanari Bó: http://www.senac.br/INFORMATIVO/BTS/313/boltec313c.html, sitio visitado el 27 de julio de 2014. 